\title{
Lobo-guará (Chrysocyon brachyurus): características gerais, mitológicas e seu conhecimento popular na região noroeste de Minas Gerais
}

\author{
Maned wolf (Chrysocyon brachyurus): general, mythological \\ characteristics, and its popular knowledge in the northwest region of \\ Minas Gerais
}

\author{
Saulo Gonçalves Pereira (D) ${ }^{1,2 *}$, Felipe César Araújo Machado (D) ${ }^{3}$, Daniela Cristina Silva Borges (D) ${ }^{1,4}$, André Luiz \\ Quagliatto Santos (D) ${ }^{5}$, Wanderson Alves Pereira (D) ${ }^{4}$, José Onício Rosa da Silva (D) ${ }^{2}$ \\ ${ }^{1}$ Universidade Federal de Uberlândia (UFU), Uberlândia, MG, Brasil \\ ${ }^{2}$ Faculdade Patos de Minas (FPM), Patos de Minas, MG, Brasil \\ ${ }^{3}$ Centro Universitário de Patos de Minas (UNIPAM), Patos de Minas, MG, Brasil \\ ${ }^{4}$ Faculdade Cidade de João Pinheiro (FCJP), João Pinheiro, MG, Brasil \\ ${ }^{5}$ Laboratório de Ensino em Pesquisa em Animais Silvestres, Faculdade de Medicina Veterinária, Universidade Federal de Uberlândia \\ (UFU), Uberlândia, MG, Brasil
}

\section{Resumo}

Objetivou-se fazer um levantamento sobre o lobo-guará (Chrysocyon brachyurus - Illiger, 1815), descrevendo suas características gerais e sua mitologia, além de buscar, através de entrevistas, o conhecimento das pessoas acerca do lobo-guará. O conhecimento compilado sobre as características gerais e a mitologia de animais silvestres pode colaborar para sua conservação, bem como para a educação ambiental. A metodologia adotada foi dividida em duas partes: inicialmente, pesquisa qualitativa de revisão de literatura; posteriormente, aplicação de questionário de autorrespostas a pessoas maiores de idade, voluntárias, de ambos os sexos e que tinham associação com o meio rural da região noroeste de Minas Gerais. Percebeu-se que o lobo-guará é um animal de grande importância para a fauna brasileira, sendo um animal cercado de muitas histórias e mitologias. De forma geral, as pessoas identificam o lobo-guará como um animal importante para o meio ambiente, todavia um predador de animais domésticos. Os resultados mostram que ocorreram abates por esta razão.

Palavras-chave: Lobos. Cerrado. Animais silvestres. Mito. Etnobiologia. 


\section{Abstract}

The objective of this study was to make a bibliographic survey of the Chrysocyon brachyurus (Illiger, 1815) describing its general characteristics and mythology, in addition to finding through interviews people's knowledge about the maned wolf. The compiled knowledge on the general characteristics and mythology of wild animals can contribute to its conservation, as well as to environmental education. The methodology adopted was divided into two parts: initially, a qualitative review of literature; subsequently, the application of a self-administered questionnaire to people oflegal age, volunteers of both sexes and that had an association with the rural environment of the northwest region of Minas Gerais. It was noticed that the maned wolf is an animal of great importance for the Brazilian fauna, being an organism with many stories and mythologies. In general, people identify the maned wolf as an important animal for the environment, yet a predator of domestic animals; the survey showed that slaughters have occurred because of that.

Keywords: Wolves. Cerrado. Wild animals. Myth. Etnobiology.

\section{Introdução}

O lobo-guará (Chrysocyon brachyurus) é o maior canídeo selvagem da América do Sul, encontrandose, principalmente, em áreas de cerrado e de campos abertos no Brasil, oeste da Bolívia e do Paraguai e norte da Argentina (Dietz, 1984, 1985). O C. brachyurus pertence à ordem Carnivora, que tem como características específicas a presença de báculo nos machos, dentes caninos afiados, quatro ou cinco dedos nas mãos e nos pés. Tal ordem abarca 11 famílias e 274 espécies (Pough et al., 2003; Valkenburgh, 2007).

Estudos etnobiológicos contribuem para unir os conhecimentos científicos e empíricos aos saberes tradicionais de comunidades distintas no que se refere ao meio ambiente e suas relações (Marin et al., 2003). A educação ambiental tem a função de desenvolver a compreensão do meio ambiente e analisar a intrínseca relação entre os muitos elementos que o compõem, sobretudo a fauna (Pereira, 2017).

0 conhecimento sobre as características gerais dos animais silvestres, bem como sobre sua mitologia, é de grande importância. Alguns estudos sobre o C. brachyurus têm sido realizados (Dietz, 1984; Silva, 1984; Rodrigues, 2002; Paula et al., 2013; Pereira et al., 2016), todavia, dados sobre o conhecimento popular e aspectos gerais do loboguará ainda são incipientes, sobretudo para a região em questão. Desta forma, é de grande importância aprimorar tal conhecimento, principalmente para propostas conservacionistas e de educação ambiental.

Objetivou-se, portanto, fazer um levantamento bibliográfico sobre o C. brachyurus, descrevendo suas características gerais e sua mitologia, além de buscar, através de entrevistas com moradores da zona rural de sete municípios do noroeste de Minas Gerais, sobre seu conhecimento acerca do lobo-guará.

\section{Material e métodos}

A metodologia se baseou, inicialmente, nos pressupostos da pesquisa qualitativa, através de levantamento bibliográfico de forma exploratória, e posteriormente, por meio de questionário (Minayo e Sanches, 1993). 0 levantamento das referências foi realizado em livros, artigos e internet.

Em seguida, aplicou-se questionário semiestruturado (Figura 1) de perguntas e respostas objetivas/ discursivas a 30 pessoas, cujo anonimato foi resguardado. Após a coleta de material, realizou-se a análise, interpretação e discussão dos dados.

Foram incluídos no estudo voluntários de ambos os sexos, maiores de idade e moradores das comunidades rurais de municípios com presença confirmada do lobo-guará (Lagamar, Presidente Olegário, Varjão de Minas, João Pinheiro, Lagoa Grande, Brasilândia e Paracatu). Todos os entrevistados foram convidados e só participaram da pesquisa após terem assinado o termo de consentimento livre e esclarecido, aprovado pelo comitê de ética e pesquisa CEP/FPM (CAE 91420618.0.0000.8078). 


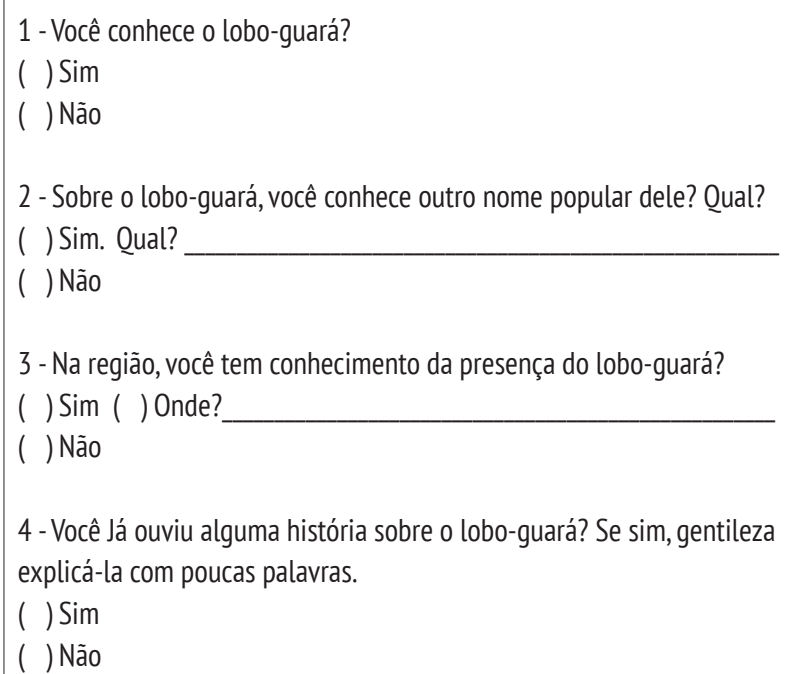

5 - Você já ficou sabendo de caso em que o lobo-guará foi morto?

( ) Sim. Por quê?

( ) Não

( ) Prefiro não dizer

6 - Você acredita que o lobo-guará esteja em perigo de extinção?

( ) Sim

( ) Não

7 - Já ficou sabendo de algum caso de ataque de lobo-guará a animais de criação na região?

( ) Sim. Qual animal?

( ) Não

8 - Você conhece alguma história mística, sobrenatural, que envolva 0 lobo-guará?

( ) Sim. Qual?

( ) Não

9 - Você acredita que o lobo-guará seja um animal ruim? Maldoso?

Perigoso?

( ) Sim. Por quê?

( ) Não

10 - Você conhece algum benefício que o lobo-guará possa trazer para a natureza?

( ) Sim. Qual?

( ) Não

Figura 1 - Questionário acerca do conhecimento popular sobre as características gerais e mitologia do lobo-guará.

\section{Resultados e discussão}

\section{Considerações sobre o lobo-guará}

O lobo-guará (Carnivora, Canidae) teve sua denominação descrita pela primeira vez por Johann Karl Wilhelm Illiger, em 1815. Illiger foi um entomólogo e zoólogo alemão que nomeou diversos canídeos e teve grande contribuição científica (Paula et al., 2013).

O nome científico Chrysocyon brachyurus (Illiger, 1815) vem do grego, onde Chrysos quer dizer "dourado"; "cyon": cachorro; brachy: "curta"; urus: "cauda", compondo o nome "cachorro-douradode-cauda-curta". No Brasil é conhecido como loboguará, que significa "lobo-vermelho" em tupi. Nos países de língua inglesa, recebe o nome de maned wolf; para os franceses, loup à crinière, e para os alemães, Mahnenwolf ("lobo-de-crina"). Para os povos latinos, Aguará guazú, que significa "cachorrogrande-vermelho" (Paula e Gambarini, 2013).

A filogenia dos lobos-guará tem uma considerável proximidade a dos cachorros domésticos (Canis familiares spp.; Linnaeus, 1758), dos lobos-do-norte (Canis sp. ou Canis lupus; Linnaeus, 1758) ou, ainda, das raposas sul-americanas (Pseudalopex sp.; Lund, 1842; ou Lycalopex sp.; Burmeister, 1854). Sua maior proximidade filogenética, porém, está ligada a de outro canídeo sul-americano, o cachorro-vinagre (Speothos venaticus; Lund, 1842), conhecido, também, como cachorro-do-mato-vinagre, canídeo que habita as florestas e pantanais desse continente (Dematteo et al., 2011; Paula e Gambarini, 2013).

Os canídeos surgiram no Eoceno superior na América do Norte, há cerca de 36 milhões de anos, e tiveram sua irradiação inicialmente para a Ásia, posteriormente para a Europa e África e, finalmente, para a América do Sul. Os fósseis mais antigos do gênero Chrysocyon, encontrados no sul dos Estados Unidos e no México, datam cerca de 5 milhões de anos. Acredita-se que o ancestral descrito Chrysocyon nearcticus tenha dado origem a uma irradiação independente à espécie $C$. brachyurus, que migrou para a América do Sul pelo estreito do Panamá, entre 3 e 2 milhões de anos atrás, onde se adaptou bem aos campos abertos desse continente, compostos por vegetação predominante do período Quaternário, da época do Pleistoceno (Motta-Junior 
et al., 1996; Wozencraft, 2005; Cubas et al., 2007; Paula e Gambarini, 2013).

Tal relação biogeográfica faz alusão à adaptação do lobo-guará às vegetações savânicas, relacionando-se sua morfologia com o substrato: pernas longas e pelagem avermelhada. Acreditase, portanto, que tal processo de distribuição biogeográfica tenha se dado também para o cachorro-do-mato-vinagre, porém a diferenciação atualmente é mais evidente, em função da adaptação das duas espécies em biomas distintos: o lobo-guará habita as áreas descampadas de cerrado predominante e o cachorro-do-matovinagre, áreas florestadas da Região Amazônica e Mata Atlântica (Carvalho, 1976; Shaw et al., 1985; Rodden et al., 2012).

A altura de $C$. brachyurus adultos varia entre 70 e $90 \mathrm{~cm}$ de cernelha, seu peso entre 20 e $35 \mathrm{~kg}$ e o comprimento do corpo entre 95 e $130 \mathrm{~cm}$. Os membros torácicos e pélvicos são longos, os pelos são grandes e predominante laranja-avermelhados, no dorso há uma crina negra e as orelhas são pontiagudas, com a parte interna de pelagens brancas. Os filhotes nascem pretos e vão mudando para pardos até o $6^{0}$ mês; a partir do $7^{0}$ mês, já desenvolvem a cor do espécime adulto. Seu focinho e parte inferior das pernas e braços são negros. Não há dimorfismo sexual aparente (Rodden et al., 2012; Pereira et al., 2016).

Os membros torácicos do C. brachyurus são alongados, sendo que o passo é classificado como "digitígrado cursorial", com andadura compassada. Os membros alongados auxiliam no deslocamento em grandes áreas. As pernas, assim como os braços, auxiliam para a caça, quando o animal corre, acelera e salta sobre suas presas (Carvalho, 1976; Hildebrand e Goslow, 2006; Paula e Gambarini, 2013; Pereira et al., 2016).

A expectativa de vida do lobo-guará em cativeiro é de 16 anos de idade; no entanto, não há informação precisa sobre essa estimativa em vida livre (Paula et al., 2013). Há relatos que em zoológicos e criadouros a expectativa de vida é de 18 anos.

O lobo-guará apresenta um padrão de atividades preferencialmente crepuscular-noturno. Classificase como onívoro, e sua dieta é composta de pequenos vertebrados e frutos. É um animal de hábito solitário em seu forrageio, sendo encontrados em dupla na época reprodutiva e durante o cuidado parietal, que é partilhado. A gestação dura até 65 dias e a ninhada tem, em média, de três a seis filhotes, com peso entre 340 e 430 g (Brady e Ditton, 1979). O C. brachyurus tem uma função importante na dispersão de sementes de frutos do cerrado, sobretudo Solanum lycocarpum, a lobeira ou fruta-do-lobo, nome este dado a sua associação com o próprio lobo-guará (Motta-Júnior et al., 2014).

Alguns estudos têm sido realizados para se estimar a área exata ocupada pelos lobosguará, sobretudo pelos casais. Conclui-se que são áreas variáveis de 6 a $115 \mathrm{~km}^{2}$, porém a áreavida das fêmeas tende a ser maior, dependendo da disponibilidade alimentar e da qualidade de habitats (Dietz, 1984; Silva, 1984; Rodrigues, 2002; Paula et al., 2013).

O C. brachyurus tinha ampla distribuição pelas áreas de campo do Brasil, no entanto, inúmeros estudos têm sido realizados para que se tenha conhecimento de sua atual distribuição. Originalmente, tal espécie estava presente no Cerrado, Chaco e Pampas, no extremo do Brasil até os limites do Cerrado com a Caatinga, Pantanal e Mata Atlântica. Atualmente, a distribuição sofreu amplas reduções na região Sul, tanto que no estado do Rio Grande do Sul a distribuição é confirmada apenas na porção sul do estado, próximo ao limite com o Uruguai, e nas regiões de campinas. Apesar de ser uma espécie sensível a alterações ambientais, alguns estudos comprovam sua adaptação a novas áreas desmatadas e de pastagem, com ênfase na Mata Atlântica e Pantanal (Chiarello et al., 2008; Paula et al., 2008; Paula e Gambarini, 2013; Paula, 2016).

O lobo-guará vive, preferencialmente, em habitats abertos, porém verifica-se sua presença no bioma Pantanal, nos ecótonos com o Cerrado e partes mais altas, assim como em ecótonos com os biomas da Mata Atlântica, em regiões alteradas e na Caatinga e Amazônia. A utilização de áreas antropizadas pode ser tanto para forrageio como para descanso (Paula et al., 2013). O lobo-guará pode, ainda, utilizar-se de áreas de campos e planícies onduladas, bem como de regiões alagadas (Carvalho, 1976). Há registros de ocorrência de $C$. brachyurus em fragmentos florestais em áreas de transição entre Cerrado e Mata Atlântica, no estado 
de São Paulo, e esse habitat pode estar servindo como refúgio da antropização (Paula et al., 2013).

Sabe-se que $90 \%$ da população de lobos-guará se encontra no Brasil. De acordo com dados da IUCN (International Union for Conservation of Nature), entretanto, a espécie está listada na categoria vulnerável, estando quase ameaçada (Paula et al., 2013; Paula, 2016).

O aumento no número de lobos-guará visualizados pelas agências ambientais em áreas próximas às cidades tem associação com o desmatamento e com as áreas destinadas à agropecuária e agricultura, fatores que pressionam os animais a procurarem comida em propriedades rurais ou cidades próximas, possibilitando sua caça e captura. Além disso, temse que o hábito de vida solitário, aliado ao ínfimo nível de agressividade, favorece a ocorrência de acidentes, como atropelamentos e tiros por arma de fogo. Várias são as causas que colocam os lobosguará como vulneráveis à extinção, podendo-se citar o crescimento desordenado de áreas urbanas e antropizadas, o que enseja a redução de habitat, bem como sua fragmentação (Diniz et al., 1999; Jácomo, 1999; Maia e Gouveia, 2002; Mattos, 2003, Queirolo e Motta-Junior, 2007; Chiarello et al., 2008; Brasil et al., 2013).

Outros fatores são importantes, porém acreditase que a falta de conhecimento, sobretudo de educação ambiental, colabore, também, para tal realidade. Contudo, algumas ações têm alcançado resultados satisfatórios na região da Serra da Canastra, em Minas Gerais, como os projetos "Lobos da Canastra" e "Sou amigo do Lobo" (Paula e Gambarini, 2013).

\section{Mitologia sobre os lobos e o lobo-guará}

Dentre os diversos predadores presentes na natureza, pode-se afirmar que o lobo é um dos mais incompreendidos. A sua história é extensa e, através de aspectos místicos, divinos e lendários atribuídos ao bem e ao mal, fez parte da cultura das principais civilizações da antiguidade.

Conhecido, principalmente, por predar animais domésticos e por causar prejuízos a pequenos produtores (Pita, 2008), o lobo foi adquirindo uma imagem negativa, reforçada após o advento dos veículos de comunicação, que disseminaram histórias que os envolviam a conotações ameaçadoras. Na mitologia egípcia, por exemplo, Anúbis ou Inpu, representado por um corpo humano com a cabeça de um canídeo, era considerado o deus dos mortos, da mumificação e do submundo (Storyteller, 2004). Acredita-se que essa associação ocorreu devido ao comportamento de cães e chacais rondando cemitérios, retirando e desmembrando os corpos das sepulturas.

Na mitologia grega, por sua vez, Zeus exilou Licáon, o rei de Arcádia, juntamente com seus filhos, transformando-os em lobos por realizarem sacrifícios humanos em prol da religiosidade e por suas práticas canibais (Ramos et al., 2017).

Na mitologia nórdica, Fenrir, filho do deus Loki e da gigante Angrboda, era um lobo colossal, bastante temido e assustador, tendo sido aprisionado pelos deuses de Asgard por causa da sua força e poder, que não paravam de crescer e, também, em razão da profecia de Ragnarok (espécie de apocalipse), que dizia que Fenrir mataria Odin e causaria o fim do mundo (Pita, 2008).

A figura do lobo foi associada a um ente com manifestações maléficas, ações destrutivas e de origem sombria na cultura de muitas civilizações. $\mathrm{Na}$ mitologia Hindu, por exemplo, o lobo era responsável por interromper a jornada da alma de um homem bom para os céus. Na Finlândia, acreditava-se que a alma perdida de uma criança que morreu sem ser batizada se transformava em lobo. Na Espanha e na Alemanha, havia o mito de que o lobo servia de montaria para bruxas e feiticeiros, e que estes eram capazes de se transformar em lobos, o que reforçou o entendimento do lobo como símbolo do diabo na Europa medieval (Ramos et al., 2017).

Devido a essas crenças, durante a idade média, assolou-se na Europa o medo em relação aos lobisomens ou licantropos, que eram homens sob influência da lua cheia que se transformavam em lobos com característica bestial. Várias cidades e vilas eram aterrorizadas por esses mitos, sendo inclusive associados a interpretações bíblicas, justificando que eles simbolizavam o mal e que eram diretamente responsáveis pelas dificuldades que existiam na época (Pita, 2008).

De acordo com Beaune (2006), o terror que o lobisomem provocou no final do século XVI influenciou a religiosidade das pessoas e, dessa 
forma, "acreditava-se que, no inferno, os que sucumbiram eram devorados pelos lobos. Obsessão pessoal, cultura clerical e espírito de partido se somam para fazer dos lobos [...] a encarnação aleatória de todos os medos daqueles tempos". Em vários lugares do mundo, onde foram disseminadas histórias de lobisomem, acreditava-se que uma pessoa se transformava em lobisomem ao se cobrir com a pele de lobo (Storyteller, 2004).

Ao lobo, agrega-se, também, um extenso significado simbólico de sorte que não representa apenas seu lado negativo, de características maléficas e violentas. Para muitas culturas, o lobo é representado como guia cósmico, animal com o poder de proteger, o elo que liga o homem à natureza e à magia, e condutor para a evolução espiritual.

Nas histórias folclóricas japonesas, os lobos eram animais bastante venerados, considerados sagrados e até mesmo tratados como deuses, chamados de ookami (grande deus). Existem muitos contos japoneses associados aos lobos, descrevendo-os como animais nobres e dignos, guardiões da natureza e protetores dos homens (Storyteller, 2004).

De acordo com Tanaka (2011), os lobos ajudavam a manter o equilíbrio ecológico de uma região, pois o aumento da população de outros animais, como javalis e veados, poderia trazer prejuízos para as colheitas. Além disso, quando os camponeses avistavam um lobo, era-lhe atribuída a seguinte prece: "Senhor Lobo, por favor, nos proteja e detenha os assaltos do veado e do javali".

Em relação à fertilidade, na mitologia romana, uma loba encontrou dois garotos dentro de uma cesta encalhada nas águas do rio Tibre, sendo eles os gêmeos Rômulo e Remo. A loba os acolheu, amamentou e cuidou deles até serem resgatados por um pastor; mais tarde, os irmãos fundaram uma colônia, que hoje seria Roma. Para os siberianos e para os turcos, o lobo era invocado para promover fecundidade às mulheres (Tanaka, 2011).

Os povos xamânicos turcos acreditavam que eram descendentes de lobos, pois, de acordo com a lenda, Asena, uma loba de juba azul celeste, envolveu-se com um sobrevivente de uma tribo que havia na China e teve 10 filhotes que eram meio humanos e meio lobos. Desse nascimento em diante, deu-se origem ao povo turco (Storyteller, 2004).
Entre os índios da tribo Ofaié do Brasil, contase a história de uma moça que se envolveu com um homem lobo e, como consequência, "mais tarde, ela dá à luz bebês-lobos que são mortos pela tribo. A mocinha é condenada à morte, mas, quando a atiraram na fogueira, transforma-se num falcão de cauda branca, que levanta voo e desaparece ao longe" (Ramos et al., 2017).

Algumas sabedorias antigas dizem que o lobo ensinou o homem a se relacionar com os seus semelhantes e com a terra, pois os lobos têm um conhecimento intuitivo da ordem no meio do caos e possuem a habilidade para sobreviver à mudança, intactos.

Os nativos americanos tinham uma imensa estima pelo lobo, considerado um símbolo espiritual poderoso, pois acreditavam que o animal descobria trilhas e era precursor de novas ideias (Levy e Machado, 1999). Para eles, a via láctea, tida como a rota do paraíso, era o caminho do lobo. A estrela Sírus (constelação Cão Maior) é a mais brilhante no céu noturno ao norte, associada ao lobo por todas as tribos. Por ser vermelha, era conhecida como a estrela que mantinha o mundo espiritual vivo, enquanto o sol iluminava o mundo físico. De acordo com Levy e Machado (1999), havia um canto de guerra dos índios das padrarias norte- americanas que dizia: "Eu sou o lobo solitário, eu vago em diversos países".

Na China, o lobo também é uma figura celeste, ante à crença de que o lobo era o guardião do portão do Palácio da Tenuidade Púrpura ou Palácio Celeste, onde o imperador do céu vivia e era representado pela constelação Ursa Maior. Segundo a Nova Acrópole (2009), os antigos chineses lançavam flechas na direção do palácio celeste quando aconteciam os eclipses, com o intuito de restabelecer a ordem no mundo obscurecido pelas trevas (Tanaka, 2011).

Em relação aos mitos da capacidade de cura, de acordo com os curandeiros, os lobos integravam a lista dos animais que possuíam propriedades medicinais, capazes de curar diversos tipos de males. Para que ocorresse a cura, porém, os lobos eram abatidos e suas partes coletadas. Essa prática era comun em regiões da Europa, América do Sul e Ásia (Paula e Gambarini, 2013). 
Dentre as crendices relacionadas ao lobo, sobretudo ao lobo-guará, as que fazem menção aos olhos são as que mais impressionam e se destacam. É dito que os olhos do lobo são fonte de poderes mágicos, capazes de hipnotizar pessoas e outros animais, o que lhe traria benefício na busca de alimentos e também na proteção contra caçadores (Andersen, 1978; Paula e Gambarini, 2013).

Ter a posse do olho de um lobo como amuleto é conhecido como forma de conquistar o amor desejado, afastar o mau agouro, trazer sorte e, em alguns lugares, acredita-se que a prática serve para prevenir ataques de serpentes. Também há citações informais de que a posse do pelo do lobo-guará afasta serpentes. Tais superstições foram passadas através de gerações e difundidas em famílias interioranas do Brasil, principalmente das regiões Sudeste e Centro-Oeste, há mais de 100 anos (Paula e Gambarini, 2013).

No que tange à figura do lobo produzido pelos veículos de comunicação, elege-se como objeto de discussão as histórias consideradas clássicas e que foram direcionadas principalmente para o público infantil, mas que conquistaram também o público adulto.

Diferente das demais histórias citadas, os lobos da história de Mogli não eram caracterizados com fisionomias assustadoras ou com ações maléficas. Nessa história, os lobos passaram uma imagem positiva, pois o papel desenvolvido por eles foi de acolher, cuidar e ensinar o menino a sobreviver na floresta, o que remete às crenças dos nativos americanos e dos japoneses de serem animais sábios da floresta, que protegem o homem. Além disso, observa-se que existe relação com a mitologia da loba de Rômulo e Remo, na qual também ocorre manifestação de instintos maternos, e com o mundialmente conhecido "Chapeuzinho Vermelho", conto publicado pela primeira vez pelo francês Charles Perrault e posteriormente pelos Irmãos Grimm.

Em razão dos mitos e lendas em torno dos lobos, passados através de gerações, surgiram expressões populares existentes até hoje: lobo faminto não para; lobo tardio não volta vazio; comer como um lobo; ter um lobo na barriga; lobo com fome qualquer coisa come; ter fome de lobo; onde um lobo acha um cordeiro, procura outro (Ramos et al., 2017).

\section{Resultado das entrevistas}

Os questionários foram aplicados aos voluntários dos municípios de Lagamar, Presidente Olegário, Varjão de Minas, João Pinheiro, Lagoa Grande, Brasilândia e Paracatu, que integram a região do noroeste de Minas Gerais. A formação típica da região é a do bioma Cerrado, que é uma savana tropical, abrangendo as mais diversas fitofisionomias (Ribeiro e Walter, 1998), ocorrendo desde os campos limpos até as florestas semidecíduas. 0 clima da região é considerado tropical continental, com pluviosidade média de $1380 \mathrm{~mm}$, irregular ao longo do ano, com um período seco de cinco meses (de maio a setembro) e cerca de $50 \%$ da precipitação nos meses de novembro a janeiro (Nimer, 1979). A bacia predominante é a do rio São Francisco e a economia é altamente agrícola, com destaque para a produção de milho, soja, mandioca e feijão, além da criação de gado (Gonçalves, 2010).

Questionados se conheciam o lobo-guará e, em caso afirmativo, se sabiam de outro nome popular para o animal, todos os entrevistados foram unânimes em dizer que somente o conhecem pelo nome de "lobo-guará", o que reforça o regionalismo dos nomes populares, que fazem parte de uma cultura e têm suas origens em características edáficas, hídricas e da vegetação da região. No caso, lobo-guará quer dizer "lobo-vermelho", em função de sua pelagem para camuflagem nos descampados do Cerrado (Paula e Gambarini, 2013; Schultz, 2015).

Quando questionados se já ouviram "alguma história" sobre o lobo-guará, os voluntários foram convidados a explicar com poucas palavras suas impressões. Cinquenta e cinco porcento (55\%) disseram nunca ter ouvido nenhuma história, 38\% disseram ter ouvido que o lobo ataca galinheiros e o restante $(7 \%)$ contou histórias menos frequentes, tais como o lobo-guará espantar onça, ter medo de cachorro, aparecer sempre em noite de lua cheia, e que em brincaderia de roda não se pode falar seu nome.

Chama-se atenção para a associação à predação de animais domésticos, sobretudo galináceos, pois na região é costume a criação desses. Em estudos na região da Serra da Canastra, verificou-se que apenas $6 \%$ dos ataques a galinheiros é feita pelo lobo-guará; porém, assim como nos resultados aqui 
apresentados, confere-se uma imagem negativa ao lobo-guará (Paula e Gambarini, 2013).

Em algumas situações, o lobo pode se alimentar de animais domésticos (Paula et al., 2013; Paula e Gambarini, 2013; Pereira et al., 2016), no entanto tal atitude somente ocorre em função da restrição de habitat causada pela antropização, além de queimadas e seca, o que restringe sua alimentação natural de hábito onívoro. Cinquenta e dois por cento (52\%) dos entrevistados afirmaram já ter ouvido falar que lobos atacam animais de criação, mais precisamente galinheiros. Nenhum ataque a outro animal foi citado, sendo que alguns entrevistados relataram que o lobo-guará não ataca "animais maiores". Na região pesquisada é comum a criação de galináceos soltos, o que pode colaborar para esse tipo de hábito.

Todavia, não é somente o lobo-guará que se alimenta de animais domésticos. Citam-se, também, a onça-parda (Puma concolor) (Linnaeus, 1771; Mazzolli, 1993), raposa-do-campo (Lycalopex vetulus), cachorro-do-mato (Cerdocyon thous) (Linnaeus, 1766; Beisiegel, 2013) e cão doméstico. Sendo assim, percebe-se que creditar somente ao lobo a predação de animais domésticos pode ser perigoso para sua imagem e, consequentemente, para sua conservação, tendo em vista que tal predação em alguns casos também pode ser feita por cães domésticos.

Questionados sobre a presença do lobo-guará no noroeste de Minas Gerais, 73\% dos entrevistados disseram ter conhecimento e $27 \%$ disseram nunca ter ouvido falar de sua presença na região. Segundo Chiarello et al. (2008), há ocorrência do lobo-guará na região, todavia estudos sobre suas dinâmicas populacionais, quantificação de indivíduos e estado de conservação a nível regional são incipientes. Uma vez que a espécie está listada na categoria vulnerável, estando quase ameaçada, sua visualização não é facilitada (Paula et al., 2013; Paula, 2016).

Os voluntários foram questionados se tinham conhecimento de algum lobo-guará ter sido morto na região, sendo que $70 \%$ disseram não ter conhecimento, $18 \%$ preferiram não responder e apenas $12 \%$ disseram saber sobre abates do animal. As principais causas citadas foram o fato de o lobo predar galináceos, medo do animal enquanto figura mística e, ainda, porque este traz "mau agouro". As formas de execução relatadas foram por arma de fogo e por envenenamento.

A percepção negativa sobre os lobos-guará é um exagero, pois as pessoas, em geral, desconhecem a fauna e perseguem os animais quando se sentem ameaçadas. 0 lobo-guará não é um animal agressivo, não havendo relatos de ataques a pessoas. Normalmente eles rosnam, arrepiam os pelos e fogem (Paula e Gambarini, 2013).

Alguns autores se dedicaram a estudar a percepção das pessoas acerca dos animais silvestres e perceberam que existe um desconhecimento científico generalizado sobre a biodiversidade, o que possibilita que outras fontes de informação, distintas da educação científica formal, e o imaginário popular sejam, ainda, as principais fontes de conhecimento sobre animais silvestres, onde valoriza-se crendices e mitos, como verificado na presente pesquisa (Bizerril, 2000; Andriguetto e Cunha, 2004; Diniz e Tomazello, 2005; Oliveira e Corona, 2008; Paiola et al., 2012; Paula e Gambarini, 2013).

Quanto ao lobo-guará estar em perigo de extinção, 63\% dos entrevistados acreditam que sim e $37 \%$ que não. Tal percepção pode estar relacionada à pouca frequência de visualização do animal. Em relatos informais, algumas causas foram apontadas, tais como desmatamento e restrição de habitat. Paula e Gambarini (2013), em estudos realizados em outras regiões do estado, mostraram que o animal se enquadra como vulnerável à extinção e sofre várias pressões, tais como caça, atropelamentos, restrição e fragmentação de habitat, desmatamento, entre outras.

A partir do conhecimento dos entrevistados acerca da extinção, percebe-se a possibilidade de conscientização com processos de educação ambiental. Em Minas Gerais, a Deliberação Normativa COPAM no 214 estabelece as diretrizes para a elaboração e execução dos programas de educação ambiental no âmbito dos processos de licenciamento ambiental. Sendo a região de vocação agrícola, onde o licenciamento ambiental é obrigatório, essa deliberação pode colaborar com os processos educativos e, consequentemente, com a conservação do lobo-guará.

Em relação a histórias místicas sobre o loboguará, a maioria $(86 \%)$ dos entrevistados disse 
não ter conhecimento e $24 \%$ relataram algumas narrações místicas. Em resumo: “o lobo-guará aparece apenas em noite de lua cheia", sendo uma referência ao mito do lobisomem. Relatou-se, também, a história de que o "olho do lobo-guará pode trazer boa sorte", que o "dente do lobo-guará pode trazer diversas curas" e, ainda, que pode haver morte na família se o animal cruzar o caminho de um cavaleiro. Narrações semelhantes também foram expostas por Paula e Gambarini (2013) em pesquisa na região da Serra da Canastra, em Minas Gerais.

Os autores Santos-Fita e Costa-Neto (2007) dissertaram sobre a relação etnozoológica entre humanos e animais, ressaltando que tal associação advém desde a pré-história; todavia, existem relações malignas, onde os animais sofrem maus tratos em função de cultos, misticismo e superstições, o que colabora para uma percepção exacerbada sobre a fauna silvestre em geral.

Para 74\% dos entrevistados, o lobo-guará é um animal perigoso, corroborando a discussão acerca do errôneo imaginário que as pessoas têm, tendo em vista ser um animal inofensivo.

Por fim, os entrevistados foram questionados se o lobo-guará traz algum benefício para o meio ambiente, sendo que $38 \%$ se mostraram indiferentes, $16 \%$ alegaram não trazer benefício algum e $46 \%$ disseram que traz benefícios. Segundo as respostas, houve associação entre o lobo-guará e a dispersão de sementes, tendo alguns entrevistados citado a lobeira (Solanum lycocarpum). Motta-Júnior e Lombardi (1993) averiguaram uma associação protocooperativa entre a lobeira e o lobo-guará, que se mostrou apto para dispersar as sementes dessa planta.

\section{Conclusão}

Mesmo tendo uma ampla distribuição geográfica e apesar dos muitos esforços para sua conservação, o lobo-guará encontra-se vulnerável à extinção, existindo variadas causas para o decréscimo de suas populações.

Percebe-se que este animal traz consigo uma relação com o imaginário das pessoas, onde há uma construção negativa diuturnamente difundida em contos, histórias e mitos, o que colabora desfavoravelmente para sua conservação. 0 lobo e o lobo-guará têm uma representação mística expressiva, porém, de acordo com as expressões populares e com as histórias apresentadas e analisadas, ainda permanecem com a imagem de um animal faminto e traiçoeiro.

Acredita-se que o entendimento acerca da percepção da população em relação ao lobo-guará possa contribuir para a elaboração de projetos efetivos de educação ambiental, visando a difusão de conhecimento e, consequentemente, a preservação da espécie e de demais espécies silvestres.

\section{Referências}

Andersen HC. Contos de Andersen. Rio de Janeiro: Paz e Terra; 1978. $74 \mathrm{p}$.

Andriguetto AC, Cunha AMO. O papel do ensino na desconstrução de mitos e crendices sobre morcegos. Rev Eletronica Mestr Educ. Ambient. 2004;12:123-34.

Beaune C. Grandes Medos da Idade Média. Rev Historia Viva. 2006;(38):48-50.

Beisiegel BM. et al. Avaliação do risco de extinção do Cachorro-do-mato Cerdocyon thous (Linnaeus, 1766) no Brasil. Bio Brasi. 2013;3(1):138-45.

Bizerril M. Humanos no Zoológico. Cienc Hoje. 2000;28(163):64-7.

Brady CA, Ditton MK. Management and Breeding of Maned - Wolves at the National Zoological Park, Washington. Int Zoo Yrbk. 1979;19:171-6.

Brasil FBJ, Daneze ER, Moura JF, Lataro RA, Campos AG, Dias BP, et al. Osteossíntese de rádio e ulna em lobo-guará (Chrysocyon brachyurus) ferido por projétil balistico Relato de caso. Nucleus Animalium. 2013;5(2):5-15.

Carvalho CT. Aspectos faunísticos do cerrado: o loboguará (Mammalia, Canidae). Boletim Técnico, 21. São Paulo: Instituto Florestal; 1976. 18 p. 
Chiarello AG, Aguiar LMS, Gregorin R, Melo FR, Paglia A, Rodrigues FH. Mamíferos Ameaçados de Extinção em Minas Gerais, Brasil. 2008. In: Drummond GM et al. (EE.). Listas Vermelhas das Espécies da Fauna e da Flora Ameaçadas de Extinção em Minas Gerais. Belo Horizonte: Biodiversitas; 2008. 70 p.

Cubas ZS, Silva JCR, Catão-Dias JL. Tratado de animais selvagens - Medicina Veterinária. São Paulo: Roca; 2007. $1354 \mathrm{p}$.

Dematteo K, Michalski F, Leite-Pitman MRP. Bush Dog - Speothos venaticus. The IUCN Red List of Threatened Species. 2011:e.T20468A9203243 [acesso 16 jun 2018]. Disponível em: https://tinyurl.com/y7vqkchg.

Dietz JM. Chrysocyon brachyurus. Mamm Species. $1985 ; 234: 1-4$

Dietz JM. Ecology and social organization of the maned wolf (Chrysocyon brachyurus). Smithson Contr Zool. 1984;392:1-51.

Diniz EM, Tomazello MGC. Crenças e concepções de alunos de ensino médio sobre biodiversidade: um estudo de caso. Atas V ENPEC. 2005;5:1-12.

Diniz LSM, Lazzarini SM, Angelo MJ. Problemas médicoveterinários de lobo-guará (Chrysocyon brachyurus) em cativeiro. Rev Educ Contin CRMV-SP.1999;2(2):34-42.

Gonçalves MCS. As folias de Reis de João Pinheiro: Performance e identidades sertanejas no noroeste mineiro [tese]. Brasília: Universidade de Brasília; 2010. $235 \mathrm{p}$.

Hildebrand G, Goslow G. Análise da estrutura dos vertebrados. São Paulo: Atheneu; 2006. 490 p.

Jácomo ATA. Nicho alimentar do lobo-guará (Chrysocyon brachyurus Illiger, 1811) no Parque Nacional das Emas GO [dissertação]. Goiânia: Universidade Federal de Goiás; 1999.

Levy C, Machado A. A sabedoria dos animais: viagens xamânicas e mitológicas. São Paulo: Opera Prima; 1999. 296 p.
Maia OB, Gouveia AMG. Birth and mortality of maned wolves Chrysocyon brachyurus (Illiger, 1811) in captivity. Braz J Biol. 2002;62(1):25-32.

Marin AA, Oliveira HT, Comar V. A educação ambiental num contexto de complexidade do campo teórico da percepção. Interciencia. 2003;28(10):616-9.

Mattos PSR. Epidemiologia e genética populacional do lobo-guará, Chrysocyon brachyurus (Illiger, 1915) (Carnívora, Canidae) na região nordeste do Estado de São Paulo [tese]. São Carlos: Universidade Federal de São Carlos; 2003. 98 p.

Mazzolli M. Ocorrência de Puma concolor (Llnnaeus) (Felldae, Carnivora) em áreas de vegetação remanescente de Santa Catarina, Brasil. Rev Bras Zool. 1993;10(4):581-7.

Minayo MCS, Sanches O. Quantitativo-Qualitativo: oposição ou complementaridade. Cad Saude Publ. 1993;9(3):239-62.

Motta-Junior JC, Talamoni SA, Lombardi JA, Simokomaki K. Diet of the Maned Wolf, Chrysocyon brachyurus, in Central Brazil. J Zool Lond. 1996;240:277-84.

Nimer E. Climatologia do Brasil. Rio de Janeiro: IBGE, Departamento de Recursos Naturais e Estudos Ambientais; 1979. 421 p.

Nova Acrópole. 0 grande matador: a mitologia do lobo. 2009 [acesso 2 fev 2017]. Disponível em: https://tinyurl. com/yc86s4fo.

Oliveira KA, Corona HMP. A percepção ambiental como ferramenta de propostas educativas e de políticas ambientais. ANAP Brasil. 2008;1(1): 53-72.

Paiola GC, Domeneguettib L, Merlinb J, Barros JJC, Ortêncio Filho H, Magalhães Jr CAO. Percepção de moradores de cianorte sobre a prática de alimentar animais silvestres. UNOPAR Cient Cienc Human Educ. 2012;13(2):81-6.

Paula RC. Adequabilidade ambiental dos biomas brasileiros à ocorrência do lobo-guará (Chrysocyon brachyurys) e efeitos da composição da paisagem em sua ecologia espacial, atividade de movimentação [tese]. Piracicaba: Universidade de São Paulo; 2016. 199 p. 
Paula RC, Gambarini A. Histórias de um lobo. Vinhedo: Avisbrasilis; 2013. 264 p.

Paula RC, Medici P, Morato RG (Org.). Plano de ação para a conservação do lobo-guará: análise de viabilidade populacional e habitat (PHVA). Brasília: IBAMA; 2008.

Paula RC, Rodrigues FHG, Queirolo D, Jorge RPS, Lemos FG, Rodrigues LA. Avaliação do estado de conservação do Lobo-guará Chrysocyon brachyurus (Illiger, 1815) no Brasil. Biodivers Bras. 2013;3(1):146-59.

Pereira SG. Educação ambiental: faces e possibilidades de uma prática possível. Riga: Novas Edições Acadêmicas; 2017. 76 p.

Pereira SG, Santos ALQ, Borges DCS, Queiroz PRR, Silva JOR. Anatomia óssea e muscular da escapula e braço de Chrysocyon brachyurus (Carnívora, Canidae). Cienc Anim Bras. 2016;17(4):622-32.

Pita V. Ragnarok-Mitologia Nórdica. 2008 [acesso $1 \mathrm{fev}$ 2017]. Disponível em: https://tinyurl.com/y9olbdlu.

Pough H, Janis CM, Heiser JB. A vida dos vertebrados. 3 ed. São Paulo: Atheneu; 2003. 699 p.

Queirolo, D, Motta-Junior JC. Prey availability and diet of maned wolf in Serra da Canastra National Park, southeastern Brazil. Acta Theriol. 2007;52(4):391-402.

Ramos DG et al. Os animais e a psique - Volume 1: Baleia, carneiro, cavalo, elefante, lobo, onça, urso. São Paulo: Summus; 2017. 272 p.

Ribeiro JF, Walter BMT. Fitofisionomias do bioma Cerrado. In: Sano SM, Almeida SP (EE.). Cerrado: ambiente e flora. Planaltina: EMBRAPA-CPAC; 1998. p. 89-166.

Rodden M, Rodrigues F, Bestelmeyer S. Chrysocyon brachyurus. IUCN Red List of Threatened Species; 2012.
Rodrigues FHG. Biologia e conservação de lobo-guará na Estação Ecológica de Águas Emendadas, DF [tese]. Campinas: Universidade Estadual de Campinas; 2002.96p.

Santos-Fita D, Costa-Neto EM. As interações entre os seres humanos e os animais: a contribuição da etnozoologia. Biotemas. 2007;20(4):99-110.

Schultz BS. A taxonomia científica versus nome popular em Sobre algumas novas espécies de répteis e plantas brasileiras: memória de Giuseppe Raddi. Rev GTLex. 2015;1(1):184-202.

Shaw JH, Carter TS, Machado-Neto JC. Ecology of the Giant Anteater Myrmecophaga tridactyla in Serra as Canastra, Minas Gerais, Brazil: a pilot study. In: Montgomery GG (E.). Evolution and ecology of sloths, armadillos, and vermilinguas. Washington: Smithsonian Institution Press; 1985. p. 379-84.

Silva F. Mamíferos silvestres do Rio Grande do Sul. Porto Alegre: Fundação Zoobotânica do Rio Grande do Sul; 1984. 245p.

Storyteller. Lobisomem: mitos da europa, mitologia e folclore. 2004 [acesso 2 fev 2017]. Disponível em: https://tinyurl.com/y7jxveh9.

Tanaka A. Lobo Japonês - Ookami. 2011 [acesso 1 fev 2017]. Disponível em: https://tinyurl.com/y7ldatju.

Valkenburgh BV. Déjà vu: the evolution of feeding morphologies in the Carnivora. Integr Comp Biol. p. 2007;47(1):147-63.

Wozencraf WC. Order Carnivora. In: WilsonDE, Reeder DM (EE.). Mammal species of the world. 3 ed. Baltimore: The Johns Hopkins University Press; 2005. p. 532-628. 